\title{
Folha diagnóstica para avaliação do estado nutricional do feijoeiro
}

\author{
Henrique A. de Souza', Amanda Hernandes ${ }^{2}$, Liliane M. Romualdo ${ }^{3}$, \\ Danilo E. Rozane ${ }^{4}$, William Natale ${ }^{2} \&$ José C. Barbosa ${ }^{2}$
}

\begin{abstract}
RESUMO
O feijoeiro é uma planta exigente em nutrientes, seja devido ao pequeno e pouco profundo sistema radicular, seja devido ao ciclo curto. Partindo de um trabalho com doses de calcário e boro, realizaramse correlações entre dois tipos de folha $(+1$ e +3$)$ do feijoeiro, com os teores dos elementos presentes nas plantas e na produção, objetivando-se estabelecer a folha mais adequada para a diagnose foliar. $\mathrm{O}$ experimento foi desenvolvido em condições de casa de vegetação empregando-se sementes de feijoeiro cV. BRS Talismã. As doses de calcário empregadas considerando-se a saturação por bases igual a 70\%, foram calculadas como: zero de calcário, metade da dose padrão, dose para elevar $\mathrm{V}=70 \%$ (padrão), uma vez e meia a dose e duas vezes a dose padrão enquanto para o boro as quantidades aplicadas foram: zero; 0,$6 ; 1,2 ; 1,8$ e $2,4 \mathrm{mg}$ de $\mathrm{B} \mathrm{dm} \mathrm{dm}^{-3}$. Realizaram-se, no momento do florescimento, a coleta das folhas diagnósticas +1 e +3 (folhas amadurecidas a partir do ápice); a coleta de uma planta (parte aérea) por vaso e a mensuração da produção. Através de correlações constataram-se, para os nutrientes alvo do estudo, cálcio, magnésio e boro em que a folha +3 apresentou maiores coeficientes de correlação com os teores na planta e com os dados de produção.
\end{abstract}

Palavras-chave: Phaseolus vulgaris, calcário, boro

\section{Diagnostic leaf for evaluation of the nutritional status of bean}

\begin{abstract}
The bean is a nutrient demanding plant, either due to the small and shallow root system or due to the short cycle. A study with doses of lime and boron was conducted and correlations were made between two types of leaf $(+1$ and +3$)$ of the bean with the contents of these elements in plants and production, aiming to establish the most appropriate leaf for diagnosis of nutritional status. The experiment was conducted in greenhouse conditions employing bean seeds cv. BRS Talismã. Lime rates considering the saturation of bases $(70 \%)$, were calculated as zero, half the standard dose, dose to increase $\mathrm{V}=70 \%$ (default), one and a half and twice the standard dose, while the boron amounts used were: zero, 0.6, 1.2, 1.8 and $2.4 \mathrm{mg} \mathrm{B} \mathrm{dm}^{-3}$. At the time of flowering, diagnostic leaves +1 and +3 (mature leaves from the apex) were collected along with sampling of a plant (aerial part) per pot and the measurement of production. Through correlations it was verified that nutrients, calcium, magnesium and boron in the leaf +3 showed higher correlation coefficients with levels in the plant and production data.
\end{abstract}

Key words: Phaseolus vulgaris, liming, boron

\footnotetext{
EMBRAPA CAPRINOS E OVINOS, Fazenda Três Lagoas, Estrada Sobral-Groaíras, km 04, s/n, Zona Rural, CEP 62.010-970, Sobral, CE. E-mail: henrique@cnpc.embrapa.br

${ }^{2}$ UNESP/FCAV, Via de Acesso Prof. Paulo Donato Castellane, s/n, Zona Rural, CEP 14020-280, Jaboticabal, SP. E-mail: amahernandes@hotmail; natale@fcav.unesp.br; jcbarbosa@fcav.unesp.br

USP/FZEA, Av. Duque de Caxias Norte, 225, CEP 13.635-900, Pirassununga, SP. E-mail: lilianeromualdo@yahoo.com.br

${ }^{4}$ UNESP/CAMPUS EXPERIMENTAL DE REGISTRO, Rua Nelson Brihi Badur, 430, CEP 11.900-000, Registro, SP. E-mail: danilorozane@registro.unesp.br
} 


\section{INTRODUÇÃO}

É inquestionável a importância do feijão na alimentação dos brasileiros. A carência de estudos mais profundos relativos à cultura e uma insistente divulgação sobre a redução no consumo desta leguminosa, têm provocado algumas incertezas quanto ao futuro da produção e utilização desse alimento. Apesar da forte concorrência de produtos voltados mais para o mercado externo, o feijão continua numa posição de destaque no agronegócio brasileiro, de vez que responde por aproximadamente $5 \%$ da renda agrícola total situando-se como o oitavo produto em renda (Ferreira et al., 2002).

$\mathrm{O}$ feijoeiro é uma planta exigente em nutrientes, seja devido ao pequeno e pouco profundo sistema radicular ou devido ao ciclo curto. Deste modo, é fundamental que o nutriente seja colocado à disposição da planta, em tempo e local adequados (Rosolem \& Marubayashi, 1994).

A análise foliar é uma das maneiras de avaliar se o manejo adotado no solo (calagem e adubação) possui os reflexos desejados nas plantas. $\mathrm{O}$ uso adequado da análise de folhas requer a compreensão das relações entre o crescimento vegetal (ou produtividade) e a concentração de minerais nas amostras de tecido da planta (Taiz \& Zeiger, 2009).

A idéia de se usar o teor mineral de folhas como critério para a avaliação do estado nutricional, foi proposta, inicialmente, por Lagatu \& Maume (1934 a,b), em Montpellier, na França.

Para fins de levantamento do estado nutricional de uma cultura existem instruções de coleta específica da parte da planta, do estádio de desenvolvimento e do número de folhas, pois os resultados obtidos pela análise química serão comparados com valores padrões estabelecidos, denominados valores críticos ou faixas de suficiência, para então serem interpretados (Martinez et al., 1999; Malavolta et al., 1997). Contudo, para a cultura do feijão não há consenso na literatura nacional quanto à folha diagnóstica a ser coletada (Oliveira, 2004; Ambrosano et al., 1997; Malavolta et al., 1997) e/ou os critérios de amostragem nem sempre são específicos (Martinez et al., 1999) gerando, consequentemente, diferentes padrões de interpretação. Assim, partindo-se de um trabalho com doses de calcário e boro, realizaram-se correlações entre dois tipos de folha $(+1$ e +3$)$ do feijoeiro, com os teores dos elementos presentes nas plantas e a produção, com o intuito de estabelecer a folha mais adequada.

\section{MATERIAL E MÉTODOS}

O experimento foi desenvolvido em condições de casa de vegetação, na Faculdade de Ciências Agrárias e Veterinárias UNESP, campus Jaboticabal, $21^{\circ} 15^{\prime} 22^{\prime}$ 'S e 48 18 ' 58' O, que apresenta clima "Cwa" (classificação de Koppen), com sementes de feijoeiro (Phaseolus vulgaris L.) cv. BRS Talismã.
Utilizou-se amostra do subsolo de um Latossolo VermelhoEscuro distrófico A moderado, textura argilosa, relevo plano, proveniente da Fazenda Experimental de Ensino e Pesquisa FCAV/UNESP, cuja análise química para fins de fertilidade do solo é apresentada na Tabela 1.

Os tratamentos corresponderam a cinco doses de calcário e cinco doses de boro, distribuídas em esquema fatorial 5 x 5 . O delineamento experimental adotado foi em blocos casualizados, com quatro repetições; cada parcela se compunha de duas plantas, as quais foram cultivadas em vasos de polietileno com capacidade de $3 \mathrm{dm}^{3}$, conforme sugestão de Mariano et al. (1999). Utilizaram-se 10 sementes por vaso visando à obtenção de um stand de 2 plantas por vaso, sendo o desbaste realizado no estágio V2 (desdobramento das folhas primárias).

As doses de calcário empregadas foram crescentes considerando-se a saturação por bases igual a 70\% (padrão), indicada como adequada para a cultura do feijão (Ambrosano et al., 1997), sendo calculadas como segue: $\mathrm{D}_{0}=$ zero de calcário; $\mathrm{D}_{1}=$ metade da dose para elevar $\mathrm{V}=70 \% ; \mathrm{D}_{2}=$ a dose para elevar $\mathrm{V}=70 \%$ (padrão); $\mathrm{D}_{3}=$ uma vez e meia a dose para elevar $\mathrm{V}=70 \%$ e $\mathrm{D}_{4}=$ duas vezes a dose para elevar $\mathrm{V}=70 \%$, correspondendo às doses: zero; 0,$6 ; 1,2 ; 1,8$ e 2,4 $\mathrm{Mg} \mathrm{ha}^{-1}$ respectivamente. $\mathrm{O}$ calcário utilizado apresentava as seguintes características: $\mathrm{PRNT}=131 \%, \mathrm{CaO}=42 \% ; \mathrm{MgO}=25 \% ; \mathrm{PN}=$ $137 \%$ e RE $=95 \%$.

A dose padrão de boro foi igual a $1,2 \mathrm{mg} \mathrm{de} \mathrm{B} \mathrm{dm}^{-3}$ (ou kg ha-1) indicada por Mariano et al. (1999), que trabalharam com B em feijoeiro em solos de Minas Gerais. Assim, visando compor os tratamentos, utilizaram-se: $\mathrm{D}_{0}=$ zero de $\mathrm{B} ; \mathrm{D}_{1}=$ metade da dose padrão; $\mathrm{D}_{2}=$ a dose padrão; $\mathrm{D}_{3}=$ uma vez e meia a dose padrão e $\mathrm{D}_{4}=$ duas vezes a dose padrão correspondendo às seguintes doses: zero; 0,$6 ; 1,2 ; 1,8$ e 2,4 $\mathrm{mg} \mathrm{de} \mathrm{B} \mathrm{dm}^{-3}$, respectivamente. Utilizou-se, como fonte, o ácido bórico $\left(\mathrm{H}_{3} \mathrm{BO}_{3}\right)$ p.a. $(17 \% \mathrm{~B})$.

As amostras de solo foram incubadas com calcário nos respectivos tratamentos, em sacos plásticos abertos, durante 30 dias, mantendo-se a umidade constante com aplicação de água deionizada até $70 \%$ do VTP (volume total de poros); o revolvimento e a homogeneização do solo foram realizados periodicamente.

Em todos os tratamentos até mesmo na testemunha, os solos, após a incubação, foram peneirados e receberam, como

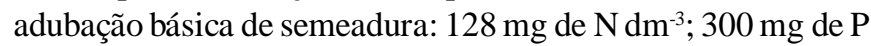

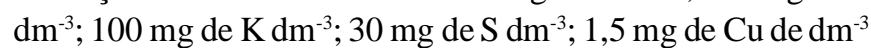
e 5,0 $\mathrm{mg}_{\text {de }} \mathrm{Zn} \mathrm{dm}{ }^{-3}$ de solo, além das respectivas doses de boro (tratamentos). A adubação de cobertura foi parcelada em três vezes, nos seguintes estágios: V3, V4 e R1 com 110 mg de $\mathrm{N}$ e $70 \mathrm{mg}$ de $\mathrm{K} \mathrm{dm}^{-3}$ de solo, sendo esses valores o somatório das três aplicações. As fontes utilizadas foram sais p.a.: nitrato de amônio, nitrato de potássio, fosfato monoamônico, cloreto de potássio, sulfato de magnésio, sulfato de cobre e sulfato de zinco, conforme indicações de Mariano et al. (1999; 2000) para ensaio em vaso.

Tabela 1. Análise de rotina, micronutrientes, enxofre e alumínio do Latossolo Vermelho-Escuro utilizado no experimento

\begin{tabular}{|c|c|c|c|c|c|c|c|c|c|c|c|c|c|c|c|c|}
\hline \multirow{2}{*}{$\begin{array}{c}\mathrm{pH} \\
\left(\mathrm{CaCl}_{2}\right)\end{array}$} & \multirow{2}{*}{$\begin{array}{l}\text { M.O. } \\
\mathrm{g} \mathrm{dm}^{-3}\end{array}$} & \multirow{2}{*}{$\begin{array}{c}\text { P (resina) } \\
\mathrm{mg} \mathrm{dm}^{-3}\end{array}$} & $K$ & $\mathrm{Ca}$ & $\mathrm{Mg}$ & $(\mathrm{H}+\mathrm{Al})$ & SB & CTC & Al & \multirow{2}{*}{$\begin{array}{l}\mathbf{V} \\
\%\end{array}$} & B & $\mathrm{Cu}$ & $\mathrm{Fe}$ & $\mathrm{Mn}$ & $\mathrm{Zn}$ & $\mathrm{S}-\mathrm{SO}_{4}{ }^{2-}$ \\
\hline & & & \multicolumn{7}{|c|}{$\mathrm{mmol}_{\mathrm{c}} \mathrm{dm}^{-3}$} & & \multicolumn{6}{|c|}{$\mathrm{mg} \mathrm{dm}^{-3}$} \\
\hline 4,3 & 5 & 3 & 1 & 4 & 2 & 23 & 7 & 32 & 4 & 22 & 0,12 & 0,2 & 5 & 3,4 & 0,1 & 35 \\
\hline
\end{tabular}


Durante o período experimental a umidade do solo foi mantida em torno de $70 \%$ do VTP, por meio de pesagens diárias dos vasos e adição de água deionizada.

Realizou-se, no momento do florescimento, a coleta das folhas diagnósticas +1 e +3 (folhas amadurecidas a partir do ápice), segundo indicações de Oliveira (2004), Malavolta et al. (1997) e Ambrosano et al. (1997), respectivamente, além da coleta de uma planta (parte aérea) por vaso.

Em seguida, as plantas (parte aérea) e as folhas $(+1$ e +3$)$ foram lavadas em água destilada e secadas em estufa com circulação forçada de ar, na temperatura de $65^{\circ} \mathrm{C} \pm 0,5$, até atingir massa constante, sendo determinada a massa seca da parte aérea da planta; na sequência se determinaram os teores de nutrientes no tecido vegetal, empregando-se a metodologia descrita por Bataglia et al. (1983).

A outra planta remanescente no vaso foi conduzida até a produção, além de colhidos os grãos na maturação fisiológica (estádio R9), determinando-se a massa seca dos grãos, o número de vagens por planta e o número de grãos por vagem.

Com base nos resultados de acúmulo de nutrientes na planta inteira e dos teores de elementos nas folhas diagnósticas, realizaram-se correlações para os três principais elementos alvo do estudo (Ca, $\mathrm{Mg}$ e B), além da correlação da produção com as folhas diagnósticas, de acordo com os testes de paralelismo (t) e coincidência (F) entre as retas.

\section{RESULTADOS E DISCUSSÃO}

Na Figura 1 se encontram a equação, o coeficiente de correlação e o valor de $\mathrm{t}$ entre o teor dos nutrientes $(\mathrm{Ca}, \mathrm{Mg}$ e B) nas folhas avaliadas $(+1 \mathrm{e}+3)$, e o teor presente no feijoeiro, ou seja, na planta inteira.

É importante ressaltar que, independente do nutriente avaliado e da correlação do teor na folha +1 ou na +3 com o teor na planta, todos os nutrientes apresentaram resultados estatisticamente significativos (Figura 1A, B e C).

$\mathrm{Na}$ Tabela 2 se encontram os testes de coincidência e paralelismo para as variáveis trabalhadas; para as comparações realizadas entre os teores de nutrientes nas folhas $+1 \mathrm{e}+3$ com o teor presente na planta verifica-se, na avaliação dos teores de $\mathrm{Ca}$ e $\mathrm{Mg}$, que as retas não são paralelas nem coincidentes, para o boro, o resultado do teste de paralelismo e coincidência foi não significativo, de modo que as retas são coincidentes. Desta forma, para as correlações entre os teores presentes nas folhas e nas plantas, para os macronutrientes ( $\mathrm{Ca}$ e $\mathrm{Mg}$ ) apresentaram maior valor de coeficiente de correlação na folha mais baixeira (+3) (Figuras 1A e 1B); já para boro independe a escolha da folha diagnóstica (Figura 1C).

Vários trabalhos com a cultura do feijoeiro foram realizados e a coleta de folha diagnóstico é sempre variável, como constatado nas pesquisas realizadas por Pegoraro et al. (2008) e Fageria (2000) em estudo com doses de B; Silva et al. (2007), Heinrichs et al. (2008), Fageria \& Stone (2004), Oliveira \& Parra (2003) e Fageria (2001), em estudos com calagem; Farinelli et al. (2006) e Ferreira et al. (2003) em estudos com adubação foliar;

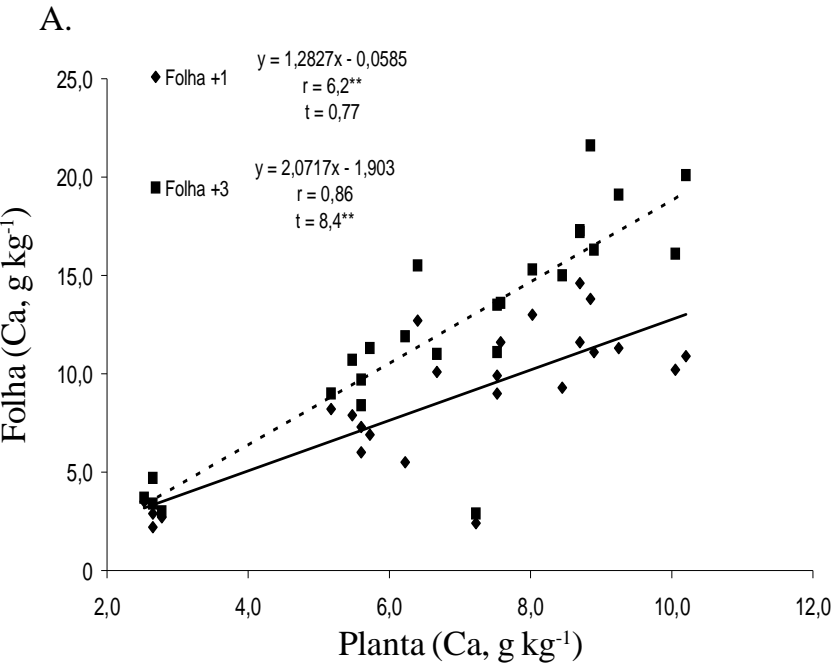

B.

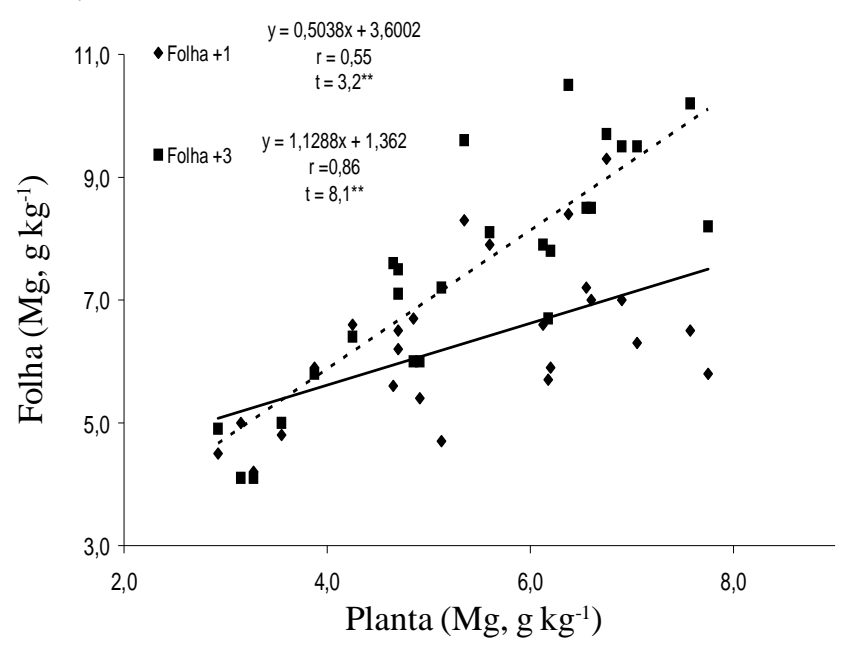

C.

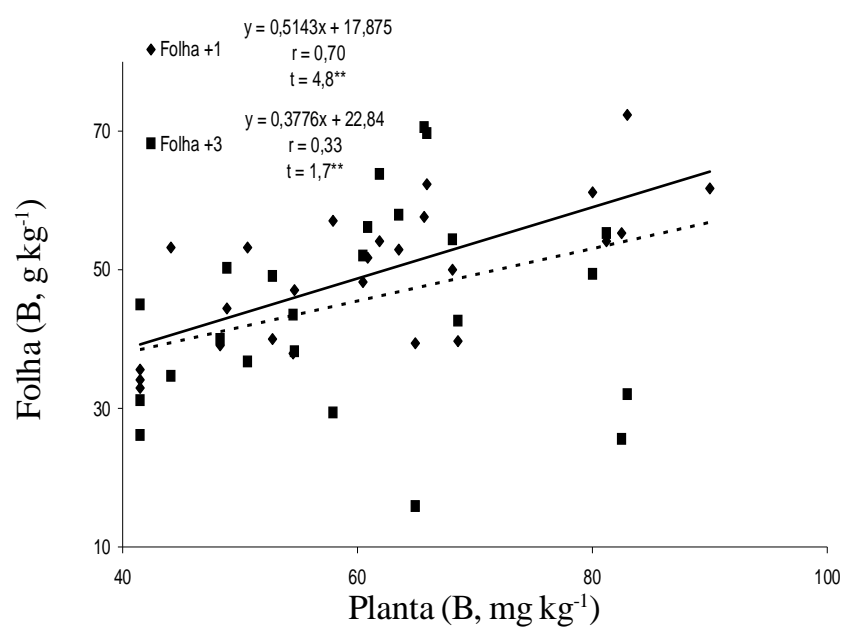

${ }^{*} e$ ** significativo a 5 e $1 \%$

Figura 1. Equações, coeficiente de correlação (r) e valor de t obtidos entre os teores de nutrientes na Folha $+1 \mathrm{e}$ +3 com o teor na planta para Ca (A), Mg (B) e B (C)

Leal \& Prado (2008) em avaliação de omissão de nutrientes; Lana et al. (2008) e Kikut et al. (2007), em estudo com micronutrientes; Sorato et al. (2004), Coelho et al. (2001), Silveira et al. (2003), Teixeira et al. (2010a; 2010b) e Calonego et al. 
Tabela 2. Teste de paralelismo (t) e de coincidência ( $F$ ) de retas das equações de teor, acúmulo, e dados de produção, entre as folhas $+1 \mathrm{e}+3$

\begin{tabular}{|c|c|c|}
\hline & $t$ & $F$ \\
\hline $\begin{array}{l}\text { Folha }+1 \text { vs Folha }+3\left(\text { Teor } \mathrm{Ca}, \mathrm{g} \mathrm{kg}^{-1}\right) \\
\text { Planta }\left(\mathrm{Ca}, \mathrm{g} \mathrm{kg}^{-1}\right)\end{array}$ & $2,45^{\star}$ & $14,32^{\star \star *}$ \\
\hline $\begin{array}{l}\text { Folha }+1 \text { vs Folha }+3\left(\text { Teor } M g, \mathrm{~g} \mathrm{~kg}^{-1}\right) \\
\text { Planta }\left(\mathrm{Mg}, \mathrm{g} \mathrm{kg}^{-1}\right)\end{array}$ & $2,98^{*}$ & $12,13^{\star *}$ \\
\hline $\begin{array}{l}\text { Folha }+1 \text { vs Folha }+3\left(\text { Teor } B, \mathrm{mg} \mathrm{kg}^{-1}\right) \\
\text { Planta }\left(\mathrm{B}, \mathrm{mg} \mathrm{kg}^{-1}\right)\end{array}$ & $0,56^{\text {ns }}$ & $0,68^{\text {ns }}$ \\
\hline $\begin{array}{l}\left.\text { Folha }+1 \text { vs Fol }+3 \text { (Teor } \mathrm{Ca}, \mathrm{g} \mathrm{kg}^{-1}\right) \\
\text { Acúmulo } \mathrm{Ca} \text { (mg por planta) }\end{array}$ & $2,35^{\star}$ & $12,61^{\star * *}$ \\
\hline $\begin{array}{l}\left.\text { Folha }+1 \text { vs Folha }+3 \text { (Teor } \mathrm{Mg}, \mathrm{g} \mathrm{kg}^{-1}\right) \\
\text { Acúmulo } \mathrm{Mg} \text { (mg por planta) }\end{array}$ & $2,64^{*}$ & $9,89^{* *}$ \\
\hline $\begin{array}{l}\text { Folha }+1 \text { vs Folha }+3\left(\text { Teor } B, \mathrm{mg} \mathrm{kg}^{-1}\right) \\
\text { Acúmulo } B \text { (ug por planta) }\end{array}$ & $2,00^{\text {ns }}$ & $2,60^{\text {ns }}$ \\
\hline $\begin{array}{l}\text { Folha }+1 \text { vs Folha }+3\left(\text { Teor } \mathrm{Ca}, \mathrm{g} \mathrm{kg}^{-1}\right) \\
\text { Número de vagens por planta }\end{array}$ & $0,95^{\text {ns }}$ & $4,62^{*}$ \\
\hline $\begin{array}{l}\text { Folha }+1 \text { vs Folha }+3\left(\text { Teor } \mathrm{Ca}, \mathrm{g} \mathrm{kg}^{-1}\right) \\
\text { Número de grãos por vagem }\end{array}$ & $0,97^{\mathrm{ns}}$ & $4,66^{\star}$ \\
\hline $\begin{array}{l}\text { Folha }+1 \text { vs Folha }+3\left(\text { Teor } \mathrm{Ca}, \mathrm{g} \mathrm{kg}^{-1}\right) \\
\text { Massa de grãos por planta }\end{array}$ & $0,85^{\text {ns }}$ & $4,96^{\star}$ \\
\hline $\begin{array}{l}\left.\text { Folha }+1 \text { vs Folha }+3 \text { (Teor } \mathrm{Mg}, \mathrm{g} \mathrm{kg}^{-1}\right) \\
\text { Número de vagens por planta }\end{array}$ & $1,16^{\mathrm{ns}}$ & $4,45^{\star}$ \\
\hline $\begin{array}{l}\text { Folha }+1 \text { vs Folha }+3\left(\text { Teor } M g, \mathrm{~g} \mathrm{~kg}^{-1}\right) \\
\text { Número de grãos por vagem }\end{array}$ & $1,18^{\text {ns }}$ & $4,49 *$ \\
\hline $\begin{array}{l}\text { Folha }+1 \text { vs Folha }+3\left(\text { Teor } M g, \mathrm{~g} \mathrm{~kg}^{-1}\right) \\
\text { Massa de grãos por planta }\end{array}$ & $0,73^{\text {ns }}$ & $4,31^{\star}$ \\
\hline $\begin{array}{l}\text { Folha }+1 \text { vs Folha }+3\left(\text { Teor } B, \mathrm{mg} \mathrm{kg}^{-1}\right) \\
\text { Número de vagens por planta }\end{array}$ & $0,27^{\text {ns }}$ & $0,45^{\mathrm{ns}}$ \\
\hline $\begin{array}{l}\text { Folha }+1 \text { vs Folha }+3\left(\text { Teor } B, \mathrm{mg} \mathrm{kg}^{-1}\right) \\
\text { Número de grãos por vagem }\end{array}$ & $0,28^{\text {ns }}$ & $0,46^{\text {ns }}$ \\
\hline $\begin{array}{l}\text { Folha }+1 \text { vs Folha }+3\left(\text { Teor } B, \mathrm{mg} \mathrm{kg}^{-1}\right) \\
\text { Massa de grãos por planta }\end{array}$ & $0,58^{\text {ns }}$ & $0,57^{\text {ns }}$ \\
\hline
\end{tabular}

ns, * e $^{* *}$ - Não significativo, significativo a 5 e $1 \%$

(2010), em estudo com nitrogênio; Crusciol et al. (2006), em avaliação de doses de $\mathrm{S}$, dentre muitos outros ensaios. A importância de se coletar a folha correta para avaliação do estádio nutricional desta cultura ou a que melhor representa o estado nutricional do feijoeiro, é importante, sobremaneira nas tomadas de decisão quanto ao manejo da adubação.

A Figura 2 indica a correlação significativa e positiva entre o teor de nutrientes nas folhas estudadas $(+1$ e +3$)$ e o acúmulo de Ca, Mg e B, na planta.

Quando se comparam as correlações realizadas entre o teor de Ca na folha +1 e na +3 (Figura 2A) com relação ao acúmulo de cálcio na planta, observou-se que a última folha apresentou maior valor de coeficiente de correlação (r); resultado semelhante pode ser constatado para o $\mathrm{Mg}$, ou seja, o valor da correlação da folha mais nova foi inferior ao da folha +3 (Figura 2B). Com relação ao teor de boro e quanto ao acúmulo do nutriente na planta, verifica-se que o resultado foi positivo e significativo a $1 \%(r=0,60)$ (Figura 2C) somente para a folha +3 , enquanto para a folha +1 não ocorreu correlação para esta variável. Analisando os resultados da Tabela 2 para os testes de paralelismo e coincidência, observa-se comportamento semelhante ao apresentado para os teores na planta, tanto para $\mathrm{Ca}$ quanto para $\mathrm{Mg}$; as retas não são paralelas nem

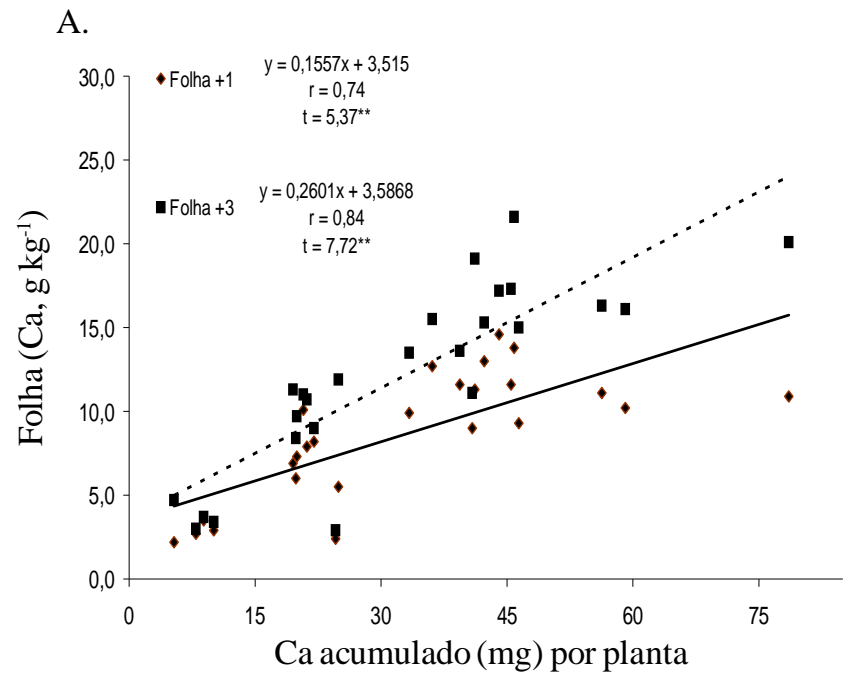

B.

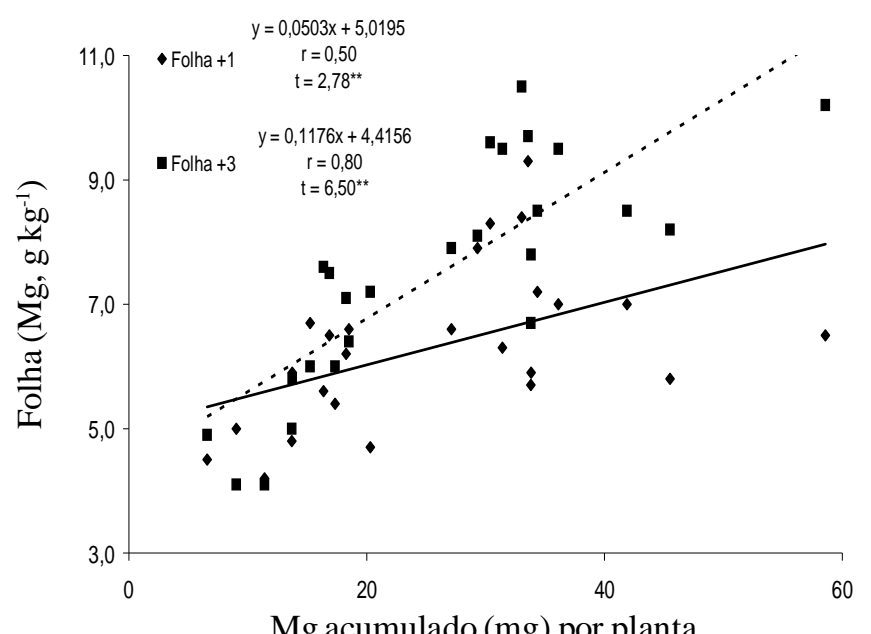

C.

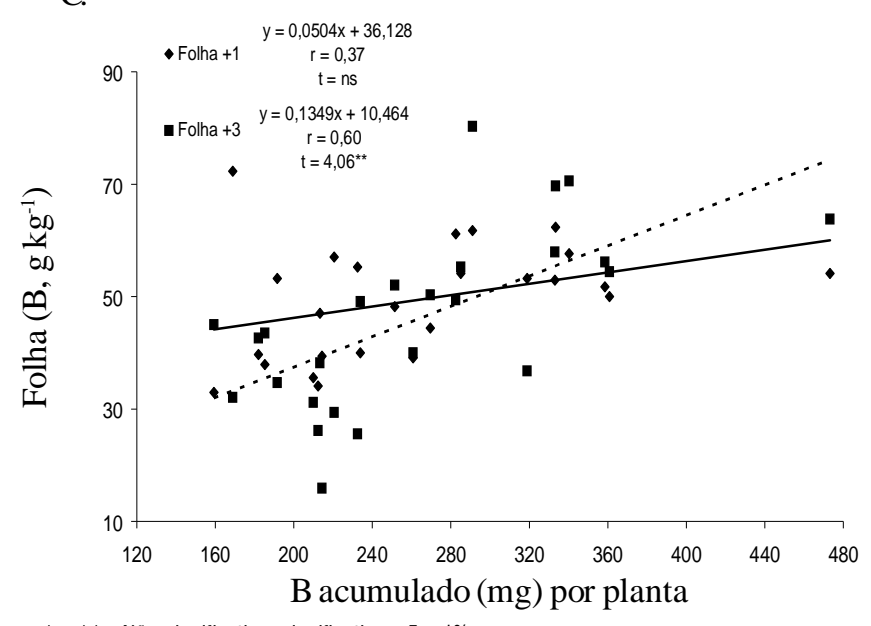

${ }^{n s,}{ }^{*} e^{* *}$ - Não significativo, significativo a 5 e $1 \%$

Figura 2. Equações, coeficiente de correlação $(r)$ e valor de $t$ obtidos entre os teores de nutrientes na Folha $+1 \mathrm{e}$ + 3 com o acúmulo na planta para o Ca (A), Mg (B) e B (C)

coincidentes e, assim, a escolha da melhor folha diagnóstico pode ser realizada pela reta que melhor interpretar os pontos, ou seja, a que apresentar maior coeficiente (Figura 2A e B), para boro novamente as retas foram coincidentes (Figura 2C). 
Uma das vantagens de se trabalhar com dados de acúmulo de nutrientes na planta é que o resultado encontrado representa a situação real do elemento presente no tecido vegetal. Afinal, o acúmulo leva em consideração a produção de massa seca da planta, de forma que efeitos de concentração ou diluição não afetarão os resultados, o que não acontece quando se comparam apenas os teores dos nutrientes presentes.

Portanto pode-se inferir, então, que para o cálcio, o magnésio e o boro, a folha +3 apresentou melhor ajuste de dados em relação ao acúmulo desses nutrientes na planta.

Entretanto, dependendo do método a ser utilizado para a interpretação dos resultados das análises químicas de tecido vegetal, o fato é que os critérios adotados para a amostragem de uma análise só poderão ser comparados com amostras retiradas na mesma época e parte da planta, uma vez que todos os métodos de interpretação consistem, basicamente, em comparar os resultados encontrados com aqueles oriundos de amostras de plantas (ou glebas) com alta produtividade (Silva, 2008).

Em avaliação da influência do estádio fenológico e da idade da folha de soja sobre a infecção por Phakopsora pachyrhizi, agente causal da ferrugem asiática em experimento de inoculação realizado nos quatro primeiros trifólios, ficou patente que o trifólio mais velho apresentou maior incidência da doença, isto é, melhor correlação com esse tipo de folha (Furtado et al., 2009).

A Figura 3 apresenta as relações do teor de cálcio em ambas as folhas $(+1 \mathrm{e}+3)$ e as características de produção (número de vagens por planta, número de grãos por vagens e massa de grãos por planta).

Quando se comparam os valores do coeficiente de correlação (r) entre o teor de Ca da folha +1 e o número de vagens por planta com aquele da folha +3 (Figura 3A), verificase que a folha mais baixeira apresentou resultado superior. Comportamento semelhante pode ser observado para número de grãos por vagem e massa de grãos por planta em relação aos teores de cálcio na folha +1 com a folha +3 (Figura 3B e 3C), respectivamente, ou seja, a folha mais madura fisiologicamente (+3) se correlacionou melhor com essas variáveis de produção. Com base nos testes de paralelismo e coincidência para as variáveis de produção, nota-se que as retas são paralelas, mas não são coincidentes (Tabela 2), de modo que apresentam a mesma tendência mesmo que elas não se sobreponham; logo, aquela que apresentar maior coeficiente de correlação representará melhor, também, os pontos, ou seja, os dados de produção.

Entre o teor de magnésio nas folhas $(+1$ e +3$)$ e a correlação com as variáveis de produção, para a folha +3 ou mais baixeira, o resultado foi significativo e positivo para todas as variáveis analisadas (Figuras 3D, E e F), enquanto para a +1 apenas para a variável massa de grãos (Figura $3 \mathrm{~F}$ ). Como constatado para as correlações realizadas entre os teores nas folhas e os dados de produção para $\mathrm{Ca}$, os resultados para $\mathrm{Mg}$ são semelhantes para os testes de paralelismo e coincidência (Tabela 2).
Para a correlação entre o teor de boro nas folhas e as variáveis de produção não houve resultados significativos; já para a avaliação de paralelismo e coincidência, o resultado é não significativo; logo, as retas são coincidentes (Tabela 2).

Assim como a época de amostragem, a posição da folha na planta a ser coletada também apresenta diferentes recomendações. Há de se observar, ainda, se as indicações de coleta de folhas indicadas na literatura correspondem a folhas inteiras (limbo e pecíolo), ou só a parte da folha (limbo ou pecíolo) (Silva, 2008); para o feijoeiro, tanto Ambrosano et al. (1997), quanto Oliveira (2004), recomendam a coleta de folhas (com o pecíolo) no florescimento da cultura. Há, ainda, outras recomendações para a amostragem do feijoeiro, como a de Malavolta et al. (1997) que recomendam, no início do florescimento, a coleta da folha recém-madura mais alta; Martinez et al. (1999) sugerem a amostragem de folhas no terço mediano da planta na época do florescimento; tais citações indicam haver recomendações para a coleta de folhas embora algumas delas não deixem claro qual deve ser amostrada.

Em outras culturas também foram realizados estudos com o fim de identificar a melhor folha para a diagnose como, por exemplo, para carambola (Prado \& Natale, 2004); coqueiro (Teixeira \& Silva, 2003); goiabeira (Natale et al., 1994); mudas de goiabeira (Rozane et al., 2009) e algodoeiro (Silva et al., 2009) e Silva (2008), em revisão extensa sobre folhas-índice; para diagnóstico nutricional e épocas de amostragem constataram-se grande variação nas indicações da literatura para diversas culturas. Portanto, há necessidade de estudos para o estabelecimento da folha diagnóstica como da época de coleta.

A cultura do algodoeiro também apresenta ambiguidades quanto à coleta de folhas podendo ser a $5^{\circ}$ folha na haste principal ou a folha adjacente à estrutura reprodutiva na época do florescimento. Em avaliação com doses de $\mathrm{N}$ na cultura, determinaram-se a melhor folha a se coletar e a época de amostragem, sendo a correlação mais estreita obtida entre a produção e a quinta folha da haste principal (Silva et al., 2009).

A importância da determinação da melhor folha diagnóstica é imprescindível não apenas para a comparação dos teores com os valores padrões mas também para uma série de avaliações, seja a diagnose visual ou mesmo índices espectrais. Baesso et al. (2007) avaliaram índices espectrais em folhas de feijoeiro em função de doses de $\mathrm{N}$, sendo possível avaliar também o estado nutricional desses nutrientes, através da referida técnica.

De maneira geral, pode-se constatar que a folha +3 do feijoeiro apresentou maior número e valores de correlação, quando comparada com a +1 ; a folha +1 , ou a primeira completamente expandida ou amadurecida, pode ainda não estar no estádio ou na maturação mais adequada para a representação do estado nutricional adequado do feijoeiro porém se deve levar em conta que, quando da realização da coleta de material para a análise foliar e a comparação com os valores do laudo com índices ou faixas de suficiência, é necessário atentar para o tipo de tecido amostrado e para a época. 
A.

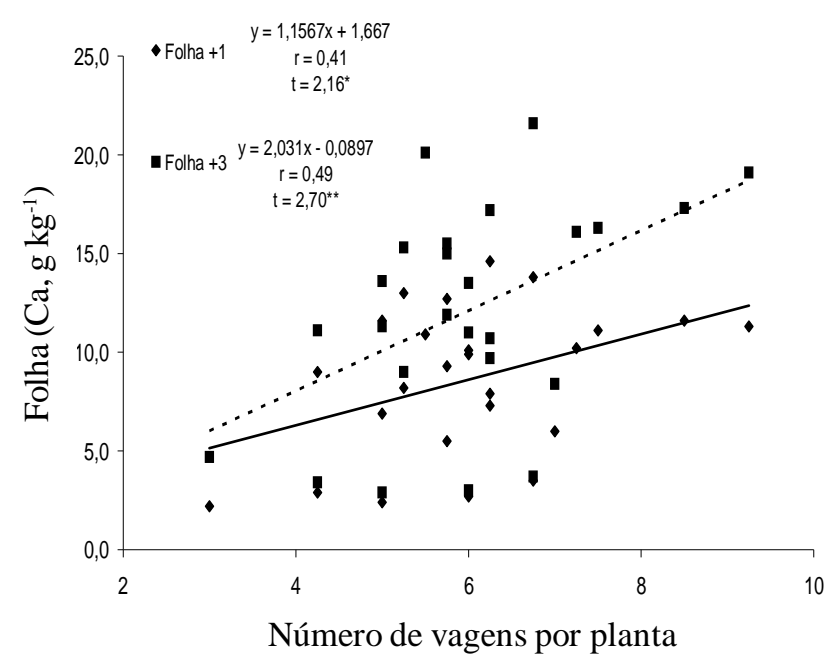

B.

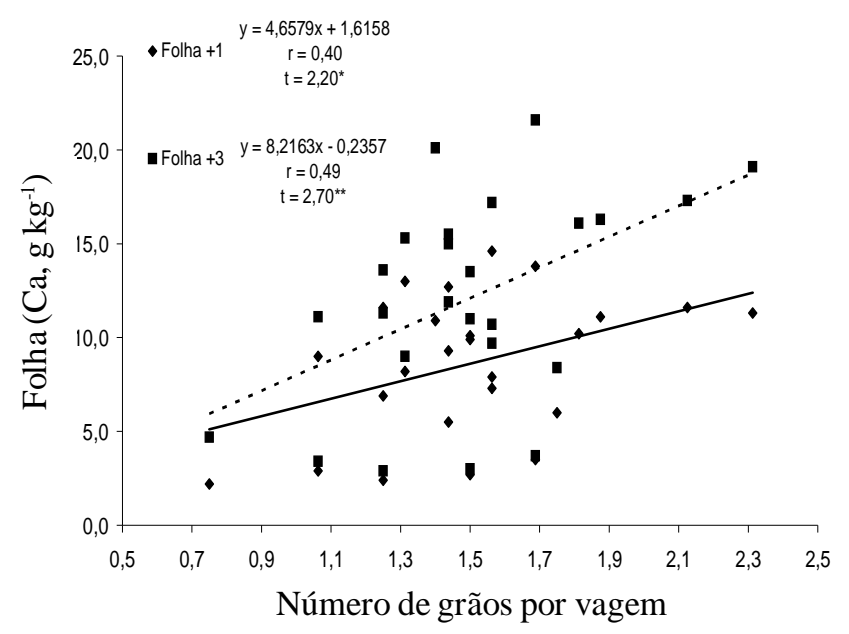

C.

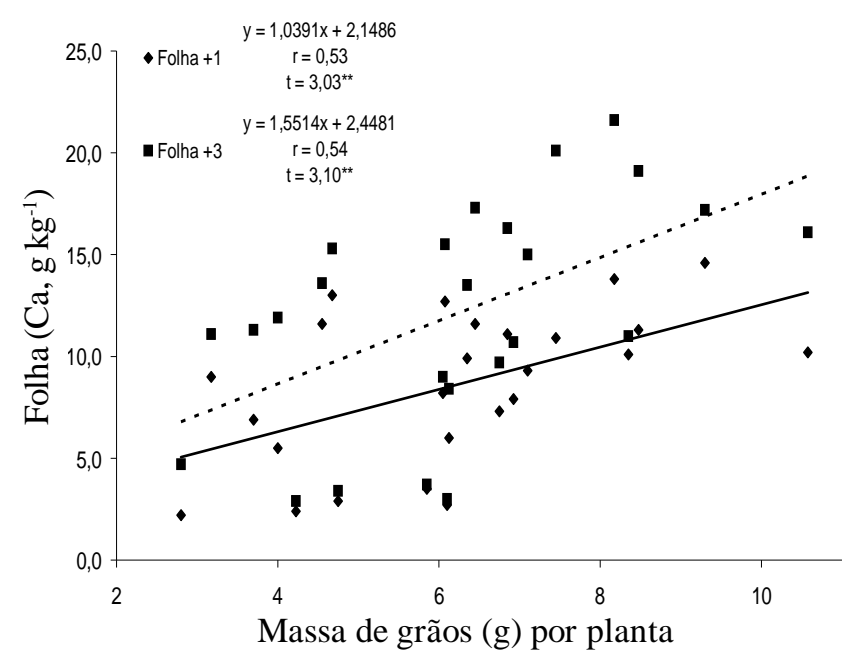

D.

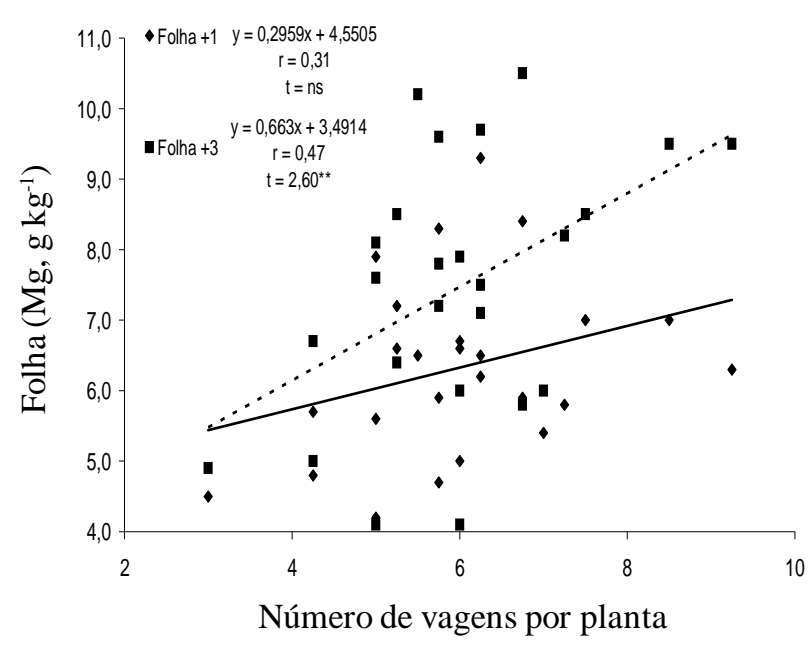

E.

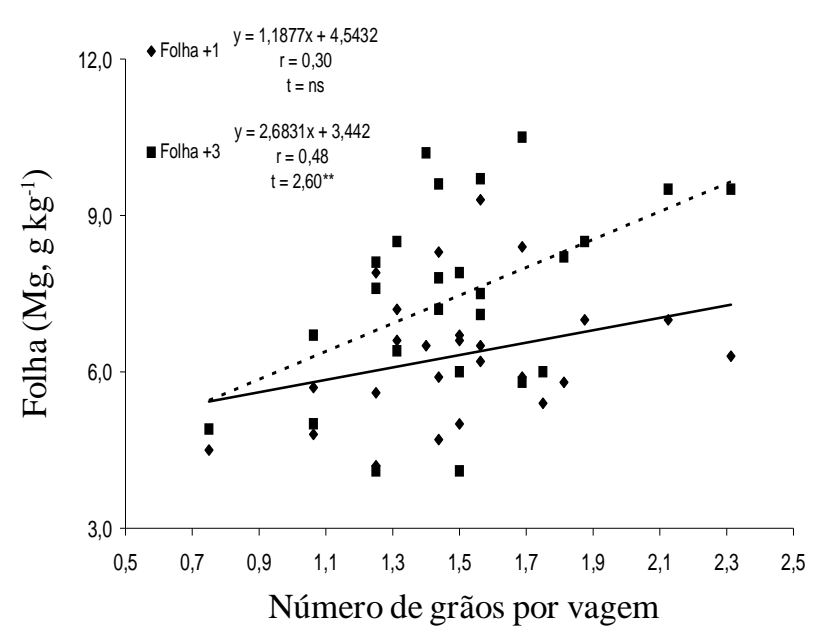

F.

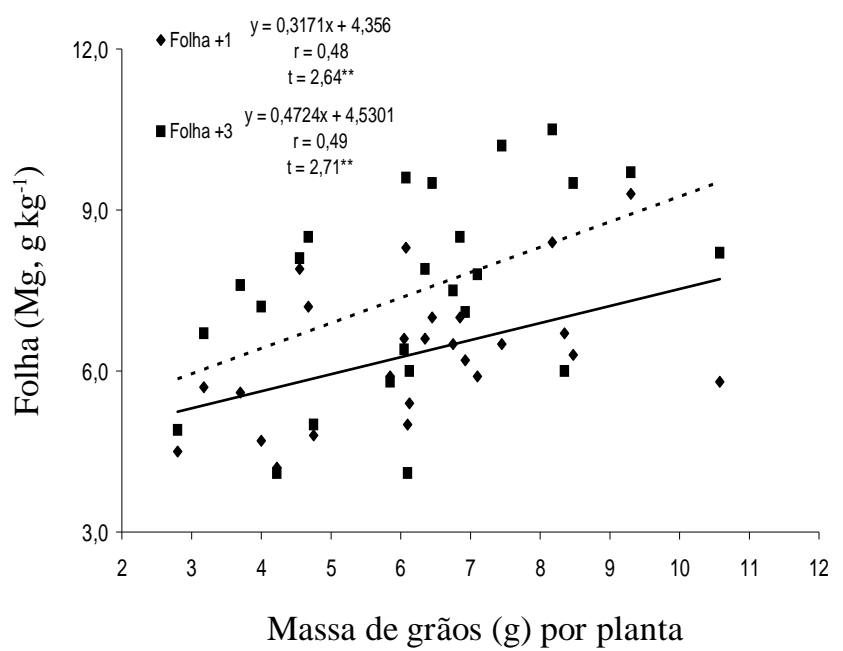

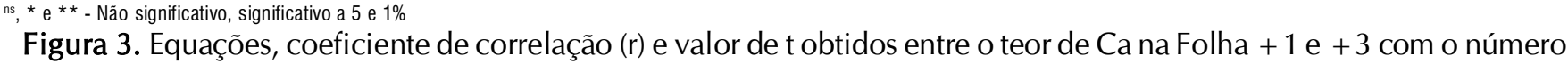
de vagens por planta (A); entre o teor de Ca na Folha +1 e +3 com o número de grãos por vagem (B); entre o teor de Ca na Folha +1 e +3 com a massa de grãos por planta (C); entre o teor de Mg na Folha +1 e +3 com o número de vagens por planta (D); entre o teor de Mg na Folha +1 e +3 com o número de grãos por vagem (E) e entre o teor de Mg na Folha +1 e +3 com a massa de grãos por planta $(F)$ 


\section{CONCLUSÕES}

1. Ambas as folhas apresentaram correlações significativas e positivas entre o teor foliar com o teor na planta, acúmulo e variáveis de produção do feijoeiro.

2. A folha +3 obteve coeficientes de correlação mais estreitos para teor, acúmulo e variáveis de produção.

\section{LITERATURA CITADA}

Ambrosano, E. J.; Wutke, E. B.; Bulisani, E. A.; Cantarella, H. Feijão. In: van Raij, B.; Cantarella, H.; Quaggio, J. A.; Furlani, A. M. C. (ed.) Recomendações de adubação e calagem para o Estado de São Paulo. Campinas: Instituto Agronômico \& Fundação IAC, 1997, p.194-195. Boletim Técnico, 100

Baesso, M. M.; Pinto, F. A. C.; Queiroz, D. M.; Vieira, L. B.; Alves, E. A. Determinação do "satatus" nutricional de nitrogênio no feijoeiro utilizando imagens digitais coloridas. Engenharia Agrícola, v.27, p.520-528, 2007.

Bataglia, O. C.; Furlani, A. M. C.; Teixeira, J. P. F.; Furlani, P. R.; Gallo, J. R. Métodos de análise química de plantas. Campinas: Instituto Agronômico, 1983. 48p. Boletim Técnico, 78.

Calonego, J. C.; Ramos Júnior, E. U.; Barbosa, R. D.; Leite, G. H. P.; Grassi Filho, H. Adubação nitrogenada em cobertura no feijoeiro com suplementação de molibdênio via foliar. Revista Ciência Agronômica, v.41, p.334-340, 2010.

Coelho, F. C.; Freitas, S. P.; Monerat, P. H.; Dornelles, M. S. Adubações com nitrogênio e molibdênio e do manejo de plantas daninhas. Revista Ceres, v.48, p.455-467, 2001.

Crusciol, C. A. C.; Soratto, R. P.; Silva, L. M.; Lemos, L. B. Aplicação de enxofre em cobertura no feijoeiro em sistema de plantio direto. Bragantia, v.65, p.459-465, 2006.

Fageria, N. K. Níveis adequados e tóxicos de boro na produção de arroz, feijão, milho, soja, e trigo em solo de cerrado. Revista Brasileira de Engenharia Agrícola e Ambiental, v.4, p.57-62, 2000.

Fageria, N. K. Efeito da calagem na produção de arroz, feijão, milho e soja em solo de cerrado. Pesquisa Agropecuária Brasileira, v.36, p.1419-1424, 2001.

Fageria, N. K.; Stone, L. F. Produtividade de feijão no sistema de plantio direto com a aplicação de calcário e zinco. Pesquisa Agropecuária Brasileira, v.39, p.73-78, 2004.

Farinelli, R.; Penariol, F. G.; Souza, F. S.; Piedade, A. R.; Lemos, L. B. Características agronômicas e qualidade fisiológica de sementes de cultivares de feijão adubados via foliar com cálcio e boro. Revista Científica, v.34, p.59-65, 2006.

Ferreira, A. C. B.; Araújo, G. A. A.; Cardoso, A. A.; Fontes, P. C. R.; Vieira, C. Diagnose do estado nutricional molibdico do feijoeiro em razão do molibdênio contido na semente e da sua aplicação. Revista Brasileira de Agrociência, v.9, p.397401, 2003.

Ferreira, C. M.; Del Peloso, M. J.; Faria, L. C. Feijão na economia nacional. Santo Antônio de Goiás: Embrapa Arroz e Feijão, 2002. 47p. Documentos, 135.
Furtado, G. Q.; Alves, A. M. S.; Carneiro, L. C.; Godoy, C. V.; Massola Júnior, N. S. Influência do estádio fenológico e da idade dos trifólios de soja na infecção de Phakopsora pachyrhizi. Tropical Plant Pathology, v.34, p.118-122, 2009.

Heinrichs, R.; Moreira, A.; Figueiredo, P. A. M.; Malavolta, E. Atributos químicos do solo e produção do feijoeiro com a aplicação de calcário e manganês. Revista Brasileira de Ciência do Solo, v.32, p.1157-1164, 2008.

Kikut, H.; Andrade, M. J. B.; Carvalho, J. G.; Morais, A. R.; Teiseira, I. R. Teores de micronutrientes na parte aérea do feijoeiro (cv. BRSMG Talismã) em função de doses de nitrogênio e fósforo. Ensaios e Ciência, v.11, p.117-126, 2007.

Lana, R. M. Q.; Ferreira, R. P.; Lana, A. M. Q.; Faria, M. V. Utilização de micronutrientes na cultura do feijoeiro cultivado no sistema de plantio direto. Bioscience Journal, v.24, p.58-63, 2008.

Lagatu, H. ; Maume, L. L. Le diagnostic foliare de la pomme de terre. Annales de I'Ecole Nationale d'Agriculture, v.22, p.50$158,1934 a$.

Lagatu, H. ; Maume, L. L. Recherches sur lê diagnostic foliaire. Annales de I'Ecole Nationale d'Agriculture, v.22, p.257-306. $1934 b$.

Leal, R. M.; Prado, R. M. Desordens nutricionais no feijoeiro por deficiência em macronutrientes, boro e zinco. Revista Brasileira de Ciências Agrárias, v.3, p.301-306, 2008.

Malavolta, E.; Vitti, G. C.; Oliveira, S. A. Avaliação do estado nutricional das plantas: princípio e aplicações. Piracicaba: Potafos, 1997. 3219p.

Mariano, E. D.; Faquin, V.; Furtini Neto, A. E.; Andrade, A. T.; Mariano, I. O. S. Níveis críticos de boro em solos de várzea para o cultivo do feijoeiro. Pesquisa Agropecuária Brasileira, v.35, p.1637-1644, 2000.

Mariano, E. D.; Faquin, V; Furtini Neto, A. E.; Santos, I. O.; Oliveira Júnior, M. A. C. Boro em solos de várzea do sul de minas gerais e a cultura do feijoeiro. Scientia Agricola, v.56, p.1051-1058, 1999.

Martinez, H. E. P.; Carvalho, J. G.; Souza, R. B. Diagnose foliar. In: Ribeiro, A. C.; Guimarães, P. T. G.; Alvarez V. V. H. Recomendações para uso de corretivos e fertilizantes em Minas Gerais ( $5^{\text {a }}$ aproximação). Viçosa: Comissão de Fertilidade do Solo do Estado de Minas Gerais, 1999. p.143168.

Natale, W.; Coutinho, E. L. M.; Boaretto, A. E.; Banzatto, D. A. Influência da época de amostragem na composição química das folhas de goiabeira (Psidium guajava L.). Revista de Agricultura, v.69, p.247-255, 1994.

Oliveira, E. L.; Parra, M. S. Resposta do feijoeiro a relações variáveis entre cálcio e magnésio na capacidade de troca de cátions de Latossolos. Revista Brasileira de Ciência do Solo, v.27, p.859-866, 2003.

Oliveira, S. A. Análise foliar. In: Sousa, D. M. G.; Lobato, E. (ed). Cerrado: Correção do solo e adubação. Brasília: Embrapa Informação Tecnológica, 2004. p.245-256

Pegoraro, R. F.; Santos Neto, J. A.; Silva, I. R.; Fontes, R. L. F; Faria, A. F.; Moreira, F. F. Crescimento de soja em solos em resposta a doses de boro, calagem e textura do solo. Ciência e Agrotecnologia, v.32, p.1092-1098, 2008. 
Prado, R. M.; Natale, W. Leaf sampling in carambola trees. Fruits, v.59, p.281-289, 2004.

Rosolem, C. A.; Marubayashi, O. M. Seja o doutor do seu feijoeiro. Piracicaba: POTAFOS, 1994, 4p. Encarte Agronômico, 7.

Rozane, D. E.; Souza, H. A.; Prado, R. M.; Natale, W.; Franco, C. F.; Leal, R. M. Influência do cultivar, do tipo de folha e do tempo de cultivo na medida indireta da clorofila (SPAD) em mudas de goiabeira. Ciência e Agrotecnologia, v.33, p.15381543, 2009.

Silva, L. M.; Lemos, L. B.; Crusciol, C. A. C.; Mateus, G. P.; Feltran, J. C. Crescimento radicular e absorção de micronutrientes do feijoeiro em razão da calagem. Revista Científica, v.35, p.88-105, 2007.

Silva, M. A. C. Importância dos critérios de amostragem. In: Prado, R. M.; Rozane, D. E.; Vale, D. W.; Correia, M .A. R.; Souza, H. A. (ed.). Nutrição de plantas diagnose foliar em grandes culturas. Jaboticabal: FCAV/CAPES/FUNDUNESP, 2008. p.61-82.

Silva, M. A. C.; Ecco, M.; Ruiz, J. G. C. L.; Marcante, N. C.; Oaredes Júnior, F. P.; Santos, F. P. Determinação da folha índice para avaliação do estado nutricional da cultura do algodoeiro. In: Congresso Brasileiro de Algodão, 7, 2009. Anais... Foz do Iguaçu: Embrapa Algodão, 2009. p.2.150-2.155.
Silveira, P. M.; Braz, A. J. B. P.; Didonet, A. D. Uso do clorofilômetro como indicador da necessidade de adubação nitrogenada em cobertura no feijoeiro. Pesquisa Agropecuária Brasileira, v.38, p.1.083-1.087, 2003.

Sorato, R. P.; Carvalho, M. A. C.; Arf, O. Teor de clorofila e produtividade do feijoeiro em razão da adubação nitrogenada. Pesquisa Agropecuária Brasileira, v.39, p.895901, 2004.

Taiz, L.; Zeiger, E. Fisiologia vegetal. Porto Alegre: Artmed, 2009. 848p.

Teixeira, C. M.; Carvalho, G. J.; Silva, C. A.; Andrade, M. J. B.; Paes, J. M. V. Nutrição mineral do feijoeiro sob influência de nitrogênio e palhadas de milheto solteiro e consorciado com crotalária. FAZU em Revista, v.7, p.73-79, 2010a.

Teixeira, C. M.; Carvalho, G. J.; Silva, C. A.; Andrade, M. J. B.; Paes, J. M. V. Nutrição mineral do feijoeiro em influência de nitrogênio e palhada de milheto solteiro e consorciado com feijão-de-porco. Acta Scientiraum, v.32, p.511-519, 2010b.

Teixeira, L. A. J.; Silva, J. A. A. Nutrição mineral de populações e híbridos de coqueiro (Cocus nucifera L.) cultivados em Bebedouro (SP). Revista Brasileira de Fruticultura, v.25, p.371-374. 2003. 